\title{
Robust composite nonlinear feedback for nonlinear Steer-by-Wire vehicle's Yaw control
}

\author{
Sarah 'Atifah Saruchi', Mohd Hatta Mohammed Ariff², Hairi Zamzuri', Noraishikin Zulkarnain", \\ Mohd Hanif Che Hasan ${ }^{5}$, Sheikh Muhammad Hafiz Fahami' \\ 1,2,3 Malaysia-Japan International Institute of Technology, Universiti Teknologi Malaysia, 54100 Kuala Lumpur, Malaysia \\ ${ }^{4}$ Centre for Integrated Systems Engineering and Advanced Technologies (Integra), Faculty of Engineering and Built \\ Environment, Universiti Kebangsaan Malaysia, 43600 Bangi, Selangor, Malaysia \\ ${ }^{5}$ Faculty of Electrical Engineering, Universiti Teknikal Melaka, 76100 Melaka, Malaysia \\ ${ }^{6}$ Sapura Technical Centre Sdn Bhd, Kawasan Perindustrian Bangi, 43650 Bandar Baru Bangi, Malaysia
}

Article Info

Article history:

Received May 25, 2018

Revised Nov 1, 2018

Accepted Feb 1, 2019

\section{Keywords:}

Disturbance Observer

Hardware-in-Loop

Nonlinear Steer-by-Wire

vehicle

Robust Composite Nonlinear

Feedback

Yaw rate tracking control

\begin{abstract}
Yaw control is a part of an Active Front Steering (AFS) system, which is used to improve vehicle manoeuvrability. Previously, it has been reported that the yaw rate tracking performance of a linear Steer-by-Wire (SBW) vehicle equipped with a Composite Nonlinear Feedback (CNF) controller and a Disturbance Observer (DOB) is robust with respect to side wind disturbance effects. This paper presents further investigation regarding the robustness of the combination between a CNF and a DOB in a nonlinear environment through a developed 7-DOF nonlinear SBW vehicle. Moreover, in contrast to previous studies, this paper also contributes in presenting the validation works of the proposed control system in a real-time situation using a Hardware-in-Loop (HIL) platform. Simulation and validation results show that the CNF and DOB managed to reduce the influence of the side wind disturbance in nonlinearities.
\end{abstract}

Copyright $(2019$ Institute of Advanced Engineering and Science. All rights reserved.

\section{Corresponding Author:}

Mohd Hatta Mohammed Ariff,

Malaysia-Japan International Institute of Technology,

Universiti Teknologi Malaysia, 54100 Kuala Lumpur, Malaysia

Email: mohdhatta.kl@utm.my

\section{INTRODUCTION}

The removal of mechanical linkages between the steering wheel and the front wheel system in a Steer-by-Wire (SBW) assembly can overcome the limitations of a traditional steering system [1]. For example, an Active Front Steering (AFS) system which requires no fixed relationship between the steering and the front wheels can be implemented independently without interference by the driver [2]. AFS is commonly utilised for yaw rate tracking control to enhance the manoeuvrability of the vehicle.

A Composite Nonlinear Feedback (CNF) controller is one of the various controllers that have been applied in an AFS system. CNF has strong capability in achieving a fast yaw rate tracking performance with minimal overshoot [3-7]. Other than AFS, the CNF also performed well in active anti-roll bar and wheel synchronisation systems [8-13]. However, CNF is not robust with regard to disturbances. Thus, extensive work has been carried out to solve this issue. Hassan et al. combined a reduced-order observer into the basic CNF design to eliminate disturbances in an AFS system [14]. In 2014, Huang et al. adopted an extended state observer to estimate the unknown disturbance in a servomotor speed regulation system [15]. Hu et al. proposed an Integral Sliding Mode (ISM) based on a CNF for path tracking purposes [16]. On the other hand, Saruchi et al. introduced a combination of a CNF and a disturbance observer (DOB) to form a robust CNF controller to cater for side wind disturbance effects in yaw rate tracking control [17]. However, the robust 
CNF performance was only evaluated in a linear environment by using a linear Steer-by-Wire (SBW) vehicle system. In addition, the work has only been conducted via simulation.

The main contribution of this study is to enhance the work of Saruchi et al. [17]. This study presents further robustness analysis of the combination between a CNF and a DOB in nonlinearities using a nonlinear SBW vehicle system. This study also investigates and validates the controller's performance in a real-time condition through a Hardware-in-Loop (HIL) platform.

\section{RESEARCH METHOD}

\subsection{Vehicle System Model}

Figure 1 shows the 7-DOF nonlinear vehicle model and a 2-DOF linear vehicle system model. Table 1 tabulates the parameters for both models. The nonlinear model is used as the vehicle plant, while the linear model is utilised in the design of the controller. Considering the existence of a side wind disturbance force $F_{\omega}$, the governing equations of lateral, longitudinal and yaw motions for a nonlinear vehicle system are expressed as follows:

$$
\begin{aligned}
& m \dot{v}_{y}=-m v_{x} \gamma+F_{y F R}+F_{y F L}+F_{y R R}+F_{y R L}+F_{\omega} \\
& m \dot{v}_{x}=m v_{y} \gamma+F_{x F R}+F_{x F L}+F_{x R R}+F_{x R L} \\
& I_{z} \dot{\gamma}=l_{F}\left(F_{y F R}+F_{y F L}\right)-l_{R}\left(F_{y R R}+F_{y R L}\right)+\frac{T}{2}\left(F_{x F L}-F_{x F R}\right)+\frac{T}{2}\left(F_{x R L}-F_{x R R}\right)+L_{\omega} F_{\omega}
\end{aligned}
$$

where, $v_{x}$ and $v_{\mathrm{y}}$ denote the lateral and longitudinal accelerations. Here, $F_{x i}$ and $F_{\mathrm{yi}}(\mathrm{i}=\mathrm{FR}, \mathrm{FL}, \mathrm{RR}, \mathrm{RL})$ are the tyre forces in the $\mathrm{X}$ and $\mathrm{Y}$ directions respectively, which can be related to the tractive tyre force $F_{T R i}$ and lateral tyre force $F_{L T i}$. The equation can be expressed as:

$$
\begin{aligned}
& F_{x i}=F_{T R i} \cos \delta_{f w i}-F_{L T i} \sin \delta_{f w i} \\
& F_{y i}=F_{T R i} \sin \delta_{f w i}+F_{L T i} \cos \delta_{f w i}
\end{aligned}
$$

where $\delta_{f w}$ is the front wheel angle. The equation of the wheel rotational motion is described as:

$$
I_{\omega} \dot{\omega}_{i}=-R_{\omega} F_{x i}+T_{i}
$$

where, $\omega_{i}$ is the wheel rotational speed. $T_{i}$ is the difference between the driving torque, $T_{d}$ and the braking torque, $T_{b}$.

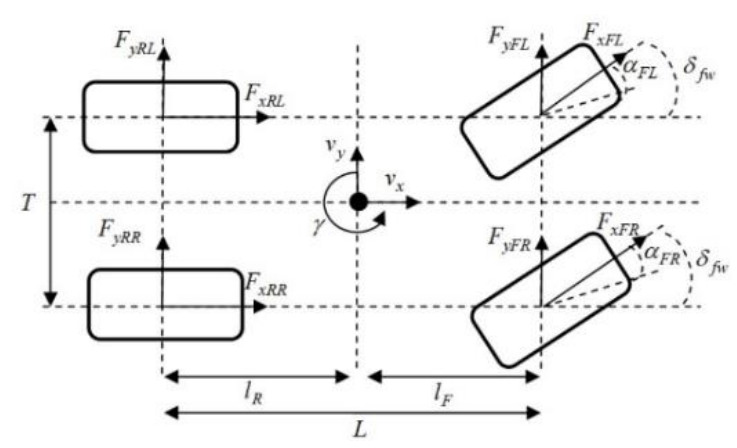

(a) Nonlinear vehicle model

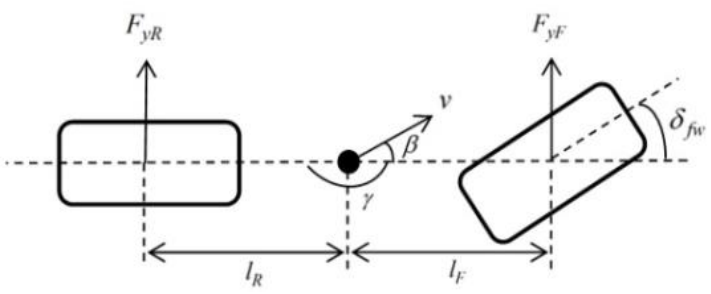

(b) Linear vehicle model

Figure 1. Structure of vehicle system models

This model includes a quasi-static load transfer to generate the normal force generations. The normal load equation for each wheel is as follows: 


$$
\begin{aligned}
& F_{Z F R, F L}=\frac{m g l_{F}}{2 L}-\frac{m \dot{v}_{x} h_{c g}}{2 L} \pm \frac{m \dot{v}_{y} h_{c g}}{2 T} \\
& F_{Z R R, R L}=\frac{m g l_{R}}{2 L}+\frac{m \dot{v}_{x} h_{c g}}{2 L} \pm \frac{m \dot{v}_{y} h_{c g}}{2 T}
\end{aligned}
$$

Table 1. Vehicle model parameters

\begin{tabular}{cccccccc}
\hline Symbol & Definition & Value & Unit & Symbol & Definition & Value & Unit \\
\hline$l_{F} \& l_{R}$ & Distance of Front \& & $1.14 \&$ & $\mathrm{~m}$ & $C_{F} \& C_{R}$ & Front \& Rear Wheel & $54500 \&$ & $\mathrm{~N} / \mathrm{rad}$ \\
& Rear Wheel to COG & 1.64 & & & Cornering Stiffness & 42600 \\
$\beta$ & Body slip angle & - & $\mathrm{rad}$ & $\gamma$ & Yaw rate & - & $\mathrm{rad}$ \\
$v_{y}$ & Lateral velocity & - & $\mathrm{ms}^{-2}$ & $I_{z}$ & Yaw Inertia & 4000 & $\mathrm{kgm}^{2}$ \\
$v_{x}$ & Longitudinal velocity & - & $\mathrm{ms}^{-2}$ & $m$ & Vehicle Mass & 1529.98 & $\mathrm{~kg}$ \\
$R_{\omega}$ & Wheel radius & 0.33 & $\mathrm{~m}$ & $L_{\omega}$ & External Force Point & 0.5 \\
$I_{\omega}$ & Wheel inertia & 2.1 & $\mathrm{kgm}^{2}$ & $F_{\omega}$ & Crosswind Force & 2000 & $\mathrm{~m}$ \\
$T$ & Track width & 1.55 & $\mathrm{~m}$ & $g$ & Gravity & 9.8 & $\mathrm{~ms}$ \\
$\alpha_{i}$ & Slip angle & - & $\mathrm{rad}$ & $h_{C G}$ & Height of c.g. & 0.54 & $\mathrm{~m}$ \\
\hline
\end{tabular}

Then, the well-known Pacejka's Magic Formula tyre model is used to obtain the responses of the nonlinear vehicle longitudinal and lateral forces [18]. On the other hand, the governing equations for the lateral and yaw motions of the linear vehicle model which is linearised from the nonlinear vehicle can be expressed as follows:

$$
\begin{aligned}
& m v((\dot{\beta}+\gamma))=-2 C_{F}\left(\beta+\frac{l_{F}}{v} \gamma-\delta_{f w}\right)-2 C_{R}\left(\beta-\frac{l_{R}}{v} \gamma\right)+F_{\omega} \\
& I_{z} \dot{\gamma}=-2 l_{F} C_{F}\left(\beta+\frac{l_{F}}{v} \gamma-\delta_{f w}\right)+2 l_{R} C_{R}\left(\beta-\frac{l_{R}}{v} \gamma\right)+L_{\omega} F_{\omega}
\end{aligned}
$$

\subsection{Front Wheel System model}

Figure 2 shows the front wheel system (FWS) configuration while Table 2 lists its parameters [19]. Basically, the FWS consists of a steering wheel, motor, rack, pinion and front wheels [20]. Input and output for the FWS system is the steering wheel angle $\delta_{s w}=\mathrm{V}$ and front wheel angle $\delta_{f w}$.

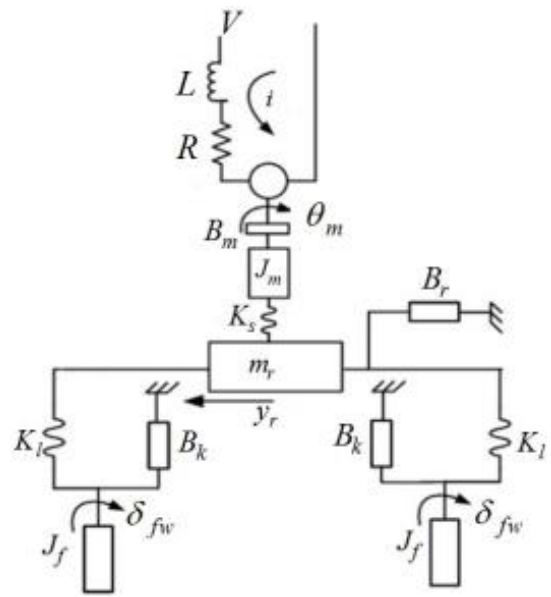

(a) Mechanism

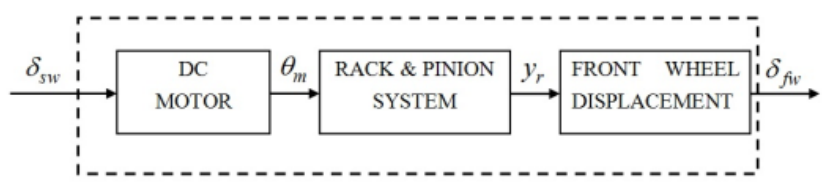

(b) Block diagram

Figure 2. Front wheel system configuration

With reference to Figure 1, the mathematical model for FWS can be expressed as:

Motor Displacement and Current:

$$
\ddot{\theta}_{m}=-\frac{1}{J_{m}}\left(B_{m} \dot{\theta}_{m}+K_{s} i\right) \quad, i=\frac{1}{L}\left(-R_{i}+K_{b} \dot{\theta}_{m}+V\right)
$$


Rack and pinion:

$$
\ddot{y}_{r}=\frac{1}{m_{r}}\left(\left(-\frac{2 K_{l}}{r_{l}} y_{r}-\frac{K_{s}}{r_{p}} y_{r}\right)-B_{r} \dot{y}_{r}-\frac{K_{s}}{r_{p}} \theta_{m}\right)
$$

Front wheel displacement:

$$
\ddot{\delta}_{f w}=\frac{1}{J_{f}}\left(-K_{l}\left(\delta_{f w}-\frac{y_{r}}{r_{l}}\right)-B_{k} \dot{\delta}_{f w}\right)
$$

(11), (12) and (13) can be represented in the following transfer function forms,

$$
\begin{gathered}
G_{1}(s)=\frac{\left(-2.274 \times 10^{-3}\right) s^{2}+\left(2.365 \times 10^{-11}\right) s}{s^{3}+506.2 s^{2}+11360 s} \\
+\frac{34390}{s^{3}+506.2 s^{2}+11360 s} \\
G_{2}(s)=\frac{\left(-3.553 \times 10^{-15}\right) s+\left(1.75 \times 10^{4}\right)}{s^{2}+12.5 s+\left(1.805 \times 10^{5}\right)} \\
G_{3}(s)=\frac{\left(1.421 \times 10^{-14}\right) s+1015}{s^{2}+51.47 s+1471}
\end{gathered}
$$

Table 2. Front Wheel System parameters

\begin{tabular}{clllclll}
\hline Symbol & Definition & Value & Unit & Symbol & Definition & Value & Unit \\
\hline$\theta_{m}$ & Motor angle & - & rad & $m_{r}$ & Rack Mass & kg & 2 \\
$V$ & Voltage & - & $\mathrm{v}$ & $r_{p}$ & Pinion gear radius & 0.1 & $\mathrm{~m}$ \\
$i$ & Motor current & - & $\mathrm{A}$ & $J_{m}$ & Motor inertia & 0.0012 & $\mathrm{kgm}^{2}$ \\
$y_{r}$ & Rack displacement & - & $\mathrm{m}$ & $J_{f}$ & Front wheel inertia & 1.36 & $\mathrm{kgm}^{2}$ \\
$m_{r}$ & Rack Mass & 2 & $\mathrm{~kg}$ & $J_{m}$ & Motor inertia & 0.0012 & $\mathrm{kgm}^{2}$ \\
$B_{m}$ & Motor damping coeff. & 0.007 & $\mathrm{Nms} / \mathrm{rad}$ & $L$ & Motor electrical induct. & 1.6663 & $\mathrm{Henry}$ \\
$K_{s}$ & Lumped torque stiff. & 0.257 & $\mathrm{Nm} / \mathrm{rad}$ & $R$ & Motor electrical resist. & 3.1124 & Ohm \\
$K_{b}$ & Motor emf constant & 0.2319 & $\mathrm{~V} \mathrm{~s} / \mathrm{rad}$ & $r$ & Offset of king pin axis & 0.69 & $\mathrm{~m}$ \\
$K_{l}$ & Steering linkage stiff. & 2600 & $\mathrm{Nm}=\mathrm{rad}$ & $B_{m}$ & Motor damping coeff. & 0.007 & $\mathrm{Nms} / \mathrm{rad}$ \\
$B_{r}$ & Rack damping coeff. & 25 & $\mathrm{Nms} / \mathrm{rad}$ & $B_{k}$ & King pin damping coeff. & 70 & $\mathrm{Nms} / \mathrm{rad}$ \\
\hline
\end{tabular}

\subsection{Controller design}

Table 3 shows parameters of the control structure. Figure 3 illustrates an overview of the control structure which includes wheel synchronisation, disturbance rejection and yaw rate tracking control systems. FWS requires a wheel synchronisation controller, $C_{1}(s)$ to control the motor position to ensure that the front wheel angle, $\delta_{f w}$ is able to synchronise with the steering input angle, $\delta_{s w}$. Here, CNF is utilised as the controller $C_{1}(s)$ [11]. In the disturbance rejection control system, a DOB is implemented to eliminate the side wind disturbance effect, $\omega$ without affecting the steering wheel. In the yaw rate tracking control system, an additional corrected angle, $\delta_{c}$ obtained from the CNF controller $C_{2}(s)$ is added to the steering input, $\delta_{s w}$ to keep the actual yaw rate response, $\gamma$ closely tracking the desired yaw rate response, $\gamma_{\text {ref }}$ generated by the reference model, $R_{2}(s)$. Detailed descriptions of the CNF and the DOB designs are explained in [17].

Table 3. Parameters of the control structure

\begin{tabular}{clll}
\hline Symbol & \multicolumn{1}{c}{ Definition } & Symbol & \multicolumn{1}{c}{ Definition } \\
\hline$\widehat{\omega}$ & Estimated side wind disturbance & $G_{4}(s)$ & Transfer function of nominal yaw model \\
$\theta_{D}$ & Disturbance compensator control input & $G_{4}^{-1}(s)$ & Inverse Transfer function of nominal yaw model \\
\hline
\end{tabular}




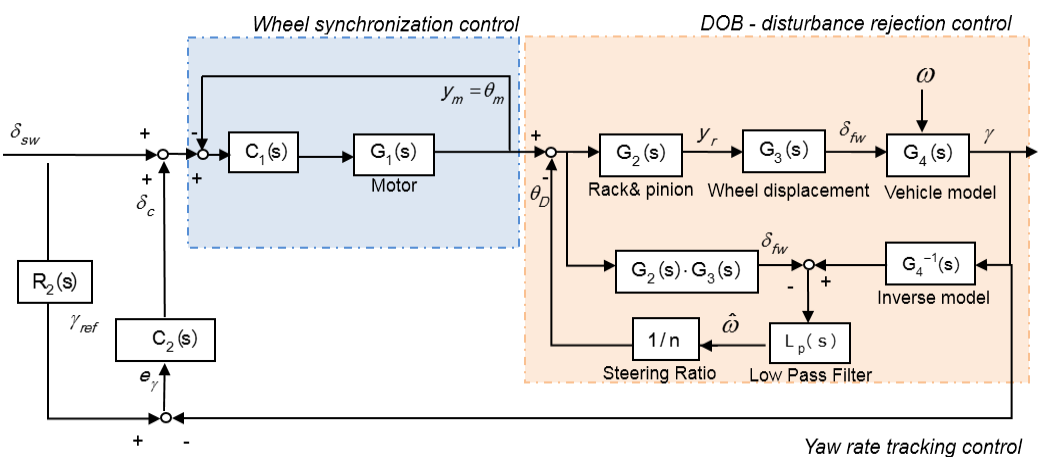

Figure 3. Overview of the control system

\subsection{Simulation setup}

The performance of a robust CNF (a combination of a CNF and a DOB) with regard to a nonlinear vehicle system can be evaluated in simulation using Matlab/Simulink software. As shown in Figure 4, the simulation is conducted for two types of manoeuvres which are J-curve and Lane change. Then, a side wind disturbance is purposely added to the manoeuvres to investigate the robustness of the controller. A comparison of the responses from the linear and nonlinear vehicle systems is conducted to investigate the yaw rate tracking abilities. During simulation, the vehicle is assumed to be running at a constant speed of $80 \mathrm{~km} / \mathrm{h}$ under normal road conditions. In order to generate the desired yaw rate response, a reference model is derived as the following $(17)[21,22]$ :

$$
\gamma_{\text {ref }}=\frac{K_{r}}{1+T_{S} S} \delta_{f w r e f}
$$

where,

$$
K_{r}=\frac{v}{L\left(1+K_{s} v^{2}\right)}, \delta_{f w r e f}=\frac{n}{T_{f w} s+1} \delta_{s w}
$$

Here, $K_{s}$ is the stability factor, $T_{s}$ is the desired time constant, $\delta_{f w r e f}$ is the desired front wheel angle, $n$ is the steering ratio, $T_{f w}$ is the delay time and $\delta_{s w}$ is the steering wheel angle.

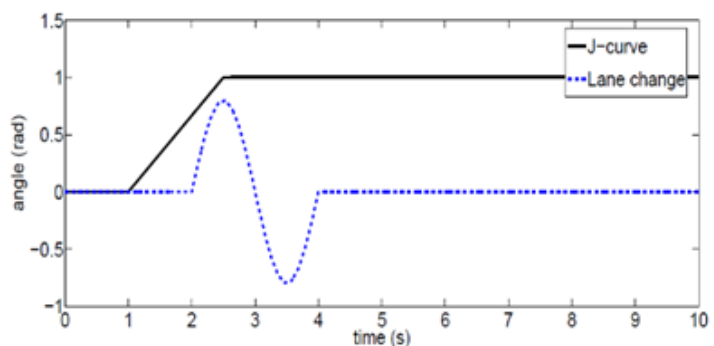

(a) J-curve and Lane change

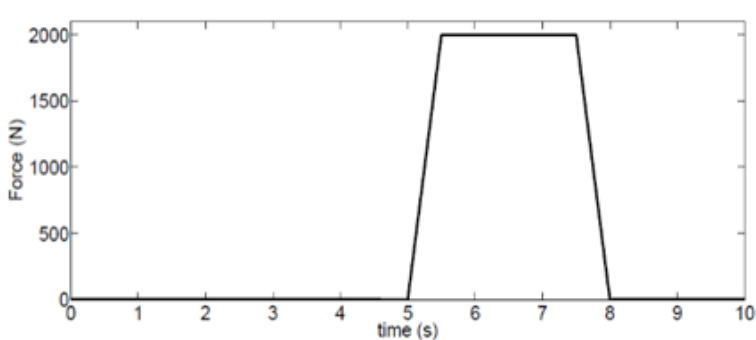

(b) Side wind disturbance

Figure 4. Input manoeuvres

\subsection{Hardware-in-Loop setup}

Figure 5 shows the overview of the Hardware-in-Loop (HIL) platform. The platform is built using a Matlab-XPC target to validate the robustness of the CNF performance in real time. During the setup, the DC motor in the FWS is replaced by a hardware mechanism while the rest of the FWS components and vehicle model remain simulated in the main PC [23]. A crossover cable is used to communicate between the main PC and the target XPC. The target monitor shows the results of the HIL test. Signals from the main PC are sent to the DC motor. Then, the signals from the DC motor are measured by the encoder and suplied to the target XPC through the NI card. 


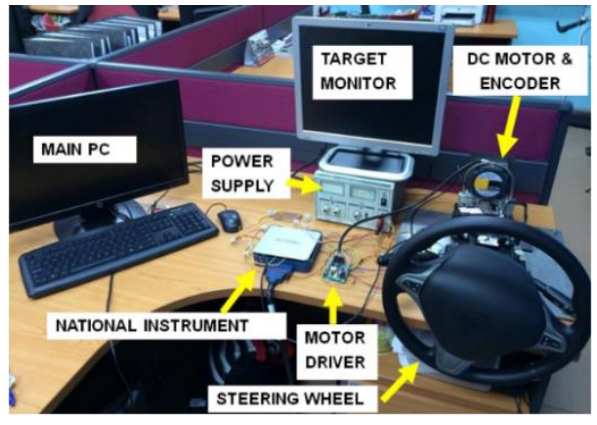

(a) HIL setup

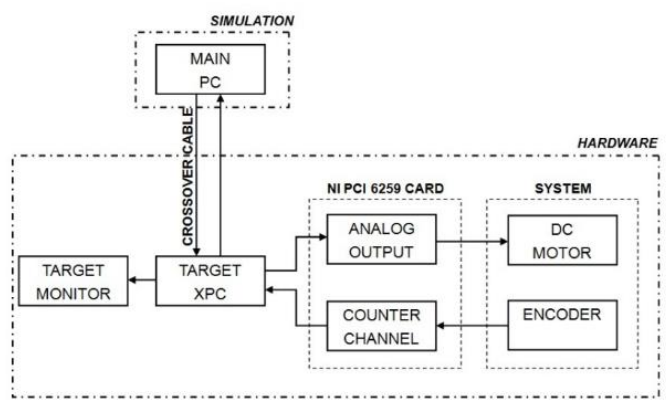

(b) HIL block diagram

Figure 5. Overview of Hardware-in-Loop (HIL)

\section{RESULTS AND ANALYSIS}

\subsection{Robustness analysis}

The effectiveness of the robust CNF performance is verified through a robustness analysis. The front and rear cornering stiffness of the vehicle model is varied to investigate the controller's robustness. The analysis is conducted in simulation using $\pm 20 \%$ of the nominal front and rear cornering stiffness parameter values $\left(C_{F}, C_{R}\right)$. Figure 6 and Figure 7 depict the yaw rate tracking responses during J-curve and Lane change manoeuvres. Both figures show that the output responses are identical to the nominal responses even though the front and rear cornering stiffness values are varied within the $\pm 20 \%$ range. The yaw rate responses increased by $3.2 \%$ and $4.5 \%$ respectively when the front and rear cornering stiffness changed to $+20 \%$, and decreased by $6.5 \%$ and $5.2 \%$ respectively when the cornering stiffness changed to $-20 \%$. However, overall, the control system is stable in both cases. Based on these results, the controller is proven to be robust under varied cornering stiffness parameters.

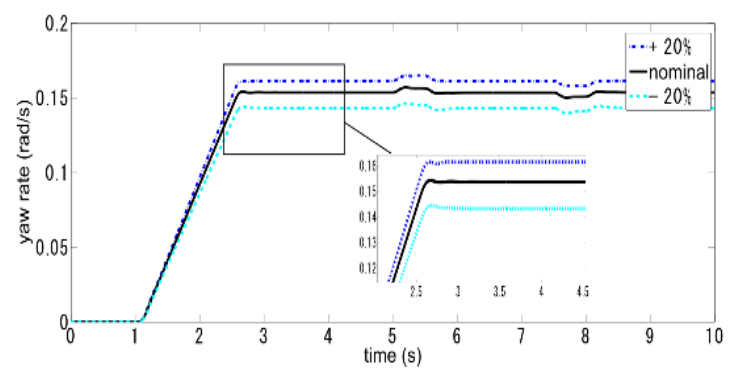

(a) Changes in front cornering stiffness, $C_{F}$

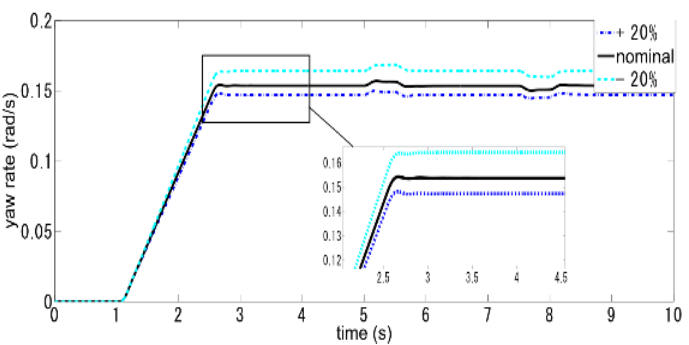

(b) Changes in rear cornering stiffness, $C_{R}$

Figure 6. Robustness analysis during a J-curve manoeuvre



(a) Changes in front cornering stiffness, $C_{F}$

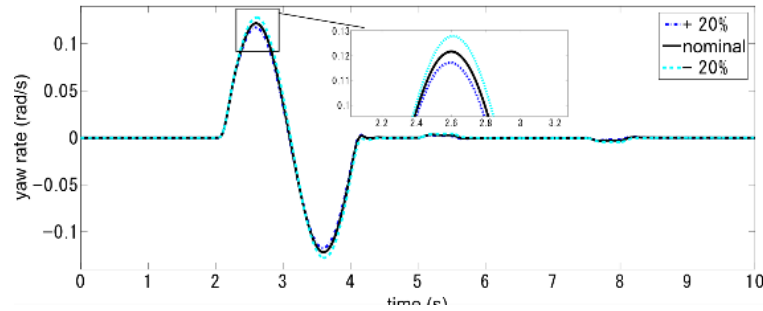

(b) Changes in rear cornering stiffness, $C_{R}$

Figure 7. Robustness analysis during a Lane change manoeuvre 


\subsection{Simulation and experiment results}

The performance analysis of the robust CNF controller in the yaw rate tracking control is carried out both in simulation and by experiment. In simulation, the control system is tested using linear and nonlinear vehicle models for comparison purposes. Then, the control system performance in the nonlinear environment is validated using a real-time HIL test. The output responses of the yaw rate tracking performance for both the simulation and experimental platforms are compared and illustrated in Figure 8(a) and 9(a). The analysis is continued by calculating the tracking error. The tracking error responses are shown in Figure 8(b) and 9(b), while the numerical results are tabulated in Table 4.

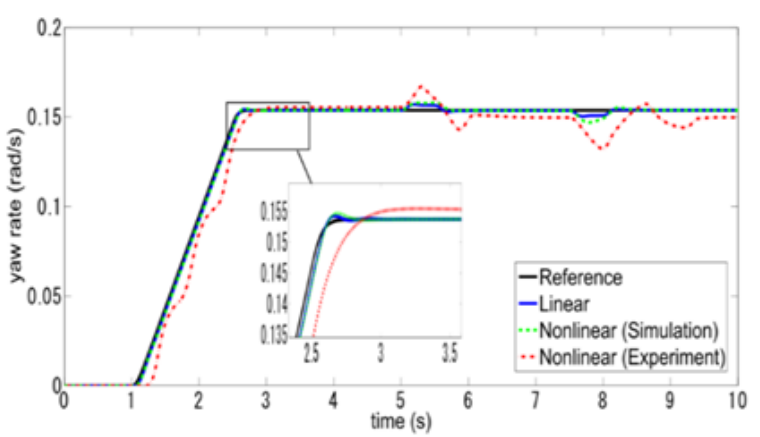

(a) Yaw rate tracking response

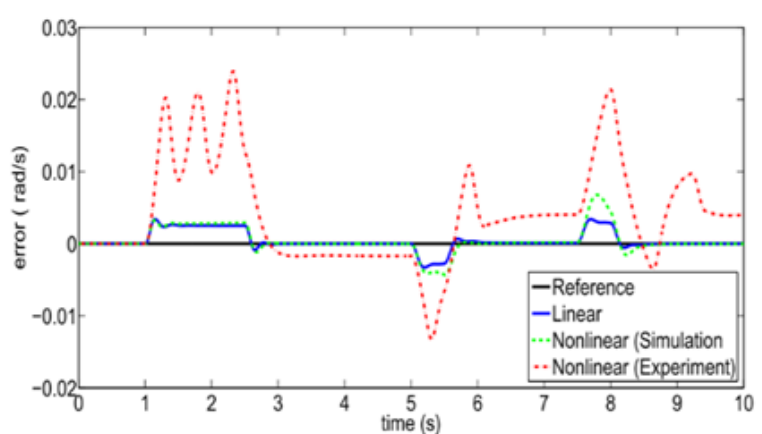

(b) Yaw rate tracking error

Figure 8. Tracking responses and errors during J-curve manoeuvre

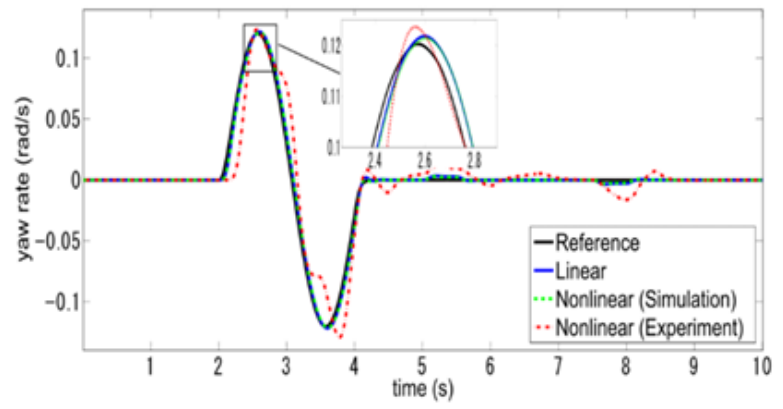

(a) Yaw rate tracking response

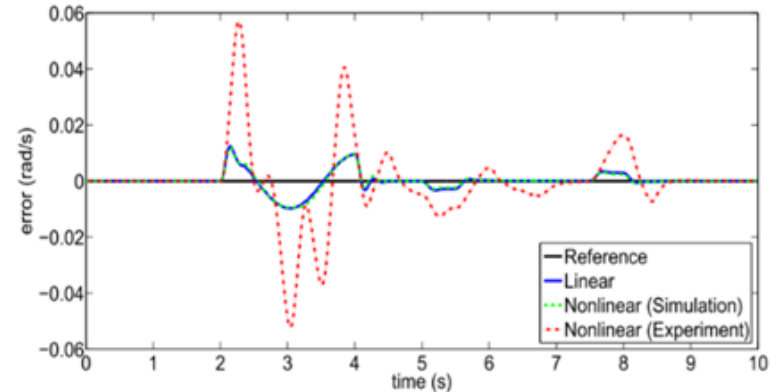

(b) Yaw rate tracking error

Figure 9. Tracking responses and errors during Lane change manoeuvre

Table 4. Analysis of Yaw rate tracking error (rms)

\begin{tabular}{ccc}
\hline Platforms & J-curve & Lane change \\
\hline Simulation (Linear) & $3.50 \times 10^{-4}$ & $2.80 \times 10^{-4}$ \\
Simulation (Nonlinear) & $4.22 \times 10^{-4}$ & $3.94 \times 10^{-4}$ \\
Experiment (Nonlinear) & $3.10 \times 10^{-3}$ & $1.60 \times 10^{-3}$ \\
\hline
\end{tabular}

Based on the tracking results for the simulation platform, it can be seen that the linear and nonlinear systems produced quite similar yaw rate output responses. On the other hand, the experimental results show that the produced yaw rate responses produced are able to track the desired signals even though there is a slightly higher overshoot and delay due to the model uncertainties such as backlash and noise. It is believed that the gap between the gears in the mechanical parts also leads to such responses.

According to the simulation results, the nonlinear system with a robust CNF controller managed to eliminate $91.13 \%$ and $97.02 \%$ of the influence caused by the side wind disturbance in the J-curve and Lane change manoeuvres, respectively. Meanwhile, based on experimental results, $78.91 \%$ and $87.88 \%$ of the disturbances effect are eliminated in both manoeuvres. 


\section{CONCLUSION}

This study presents extensive work based on a previous study by Saruchi et al. [15] by further analysis of the robustness of the combination of a CNF and a DOB in nonlinearities through the development of a nonlinear vehicle model. The analysis is then verified in real-time using a HIL platform. Simulation and experimental results prove that the $\mathrm{CNF}$ and $\mathrm{DOB}$ combination manages to closely track the desired yaw rate response with the least effect from side wind disturbance in the nonlinear condition. After being tested with J-curve and Lane change manoeuvres, $97.13 \%$ and $97.02 \%$ of the disturbances effect are reduced during simulation, while, $78.91 \%$ and $87.88 \%$ of the disturbances effect are reduced during experiment.

As for future work, it is encouraged to investigate the performance of the controller under more extreme conditions such as a double lane change manoeuvre. In terms of improvement in the accuracy of the experimental results, it is recommended to set up a HIL platform with a real rack, pinion and tyres. Additionally, the issue of model uncertainties such as backlash and noise should be further investigated and solved.

\section{ACKNOWLEDGMENT}

This work is funded by Universiti Teknologi Malaysia (UTM) Trans-Disciplinary Grant, Vote No: Q.K130000.3543.05G44.

\section{REFERENCES}

[1] Z. Yonghui and C. Dingyue, "Research on Steer-by-Wire System in Electric Vehicle," TELKOMNIKA (Telecommunication Comput. Electron. Control., vol. 15, no. 1, p. 115, 2017.

[2] I. Mousavinejad, R. Kazemi, and M. B. Khaknejad, "Nonlinear Controller Design for Active Front Steering System," Int. J. Mech. Ind. Sci. Eng., vol. 6, no. 1, pp. 1-6, 2012.

[3] M. K. Aripin, Y. M. Sam, A. D. Kumeresan, and K. Peng, "A Yaw Rate Tracking Control of Active Front Steering System Using Composite Nonlinear Feedback," Commun. Comput. Inf. Sci. Vol., vol. 402, pp. 231-242, 2013.

[4] M. K. Aripin, Y. Sam, K. A. Danapalasingam, K. Peng, N. Hamzah, and M. F. Ismail, "A Review of Active Yaw Control System for Vehicle Handling and Stability Enhancement," Int. J. Veh. Technol., vol. 2014, 2014.

[5] M. K. Aripin, Y. M. Sam, A. D. Kumeresan, M. H. Che Hasan, and M. F. Ismail, "Improving transient performances of vehicle yaw rate response using composite nonlinear feedback," J. Theor. Appl. Inf. Technol., vol. 95, no. 11, pp. 2567-2576, 2017.

[6] M. H. C. Hasan, Y. M. Sam, M. K. Aripin, M. H. Harun, and S. H. Mohamad, "Implementation of robust composite nonlinear feedback for active front steering based vehicle yaw stability," J. Teknol., vol. 79, no. 5-2, pp. 39-43, 2017.

[7] S. A. Saruchi, H. Zamzuri, S. A. Mazlan, M. H. M. Ariff, and M. A. M. Nordin, "Active Front Steering for Steerby-Wire Vehicle via Composite Nonlinear Feedback Control," IEEE 10th Asian ontrol Conf., pp. 1-6, 2015.

[8] N. Zulkarnain, F. Imaduddin, H. Zamzuri, and S. A. Mazlan, "Application of an active anti-roll bar system for enhancing vehicle ride and handling,” 2012 IEEE Colloq. Humanit. Sci. Eng., pp. 260-265.

[9] N. Zulkarnain, H. Zamzuri, M. S. Yahya, S. A. Mazlan, and S. M. H. F. Zainal, "Improving vehicle ride and handling using lqg cnf fusion control strategy for an active antiroll bar system," Abstr. Appl. Anal. Hindawi, 2014.

[10] N. Zulkarnain, H. Zamzuri, and S. A. Mazlan, "Ride and handling analysis for an active anti-roll bar: case study on composite nonlinear control strategy," Int. J. Automot. Mech. Eng., vol. 10, p. 2122, 2014.

[11] S. A. Saruchi, H. Zamzuri, S. A. Mazlan, S. M. H. Fahami, and N. Zulkarnain, "Wheel Synchronization Control in Steer-by-Wire Using Composite Nonlinear Feedback," Appl. Mech. Mater., vol. 575, pp. 762-765, Jun. 2014.

[12] N. Zulkarnain et al., "Optimised Combinatorial Control Strategy for Active Anti-Roll Bar System for Ground Vehicle,” Int. J. Eng. Technol., vol. 7, no. 4.11, pp. 140-144, 2018.

[13] N. Zulkarnain, H. Zamzuri, S. A. Saruchi, and M. M. Mustafa, "Newly Developed Nonlinear Vehicle Model for an Active Anti- roll Bar System,” Bull. Electr. Eng. Informatics, vol. 7, no. 4, pp. 529-537, 2018.

[14] M. H. Che Hasan, "An Active Front Steering Control based on Composite Nonlinear Feedback for Vehicle Yaw Stability System," Univ. Teknol. Malaysia, no. January, 2013.

[15] Y. Huang and G. Cheng, "A robust composite nonlinear control scheme for servomotor speed regulation," Int. J. Control, vol. 88, no. 1, pp. 104-112, Aug. 2014.

[16] C. Hu, R. Wang, and F. Yan, "Integral Sliding Mode-Based Composite Nonlinear Feedback Control for Path Following of Four-Wheel Independently Actuated Autonomous Vehicles," IEEE Trans. Transp. Electrif., vol. 2, no. 2, pp. 221-230, 2016.

[17] S. A. Saruchi, H. Zamzuri, N. Zulkarnain, and M. H. Mohammed, "Composite Nonlinear Feedback With Disturbance Observer for Active Front Steering,” Indones. J. Electr. Eng. Comput. Sci., vol. 7, no. 2, pp. 434-441, 2017.

[18] E. Bakker, V. C. Corp, H. B. Pacejka, and L. Lidner, "A New Tire Model with an Application in Vehicle Dynamics Studies," SAE Tech. Pap. 890087, 1989.

[19] S. M. H. Fahami, H. Zamzuri, S. A. Mazlan, and M. A. Zakaria, "Modeling and simulation of vehicle steer by wire system," in 2012 IEEE Symposium on Humanities, Science and Engineering Research, 2012, pp. 765-770. 
[20] H. Wang, S. Member, H. Kong, and Z. Man, "Sliding Mode Control for Steer-by-Wire Systems With AC Motors in Road Vehicles," IEEE Trans. Ind. Electron., vol. 61, no. 3, pp. 1596-1611, 2014.

[21] M. H. Mohammed Ariff, H. Zamzuri, N. R. Nik Idris, S. A. Mazlan, and M. A. Mohamad Nordin, "Direct Yaw Moment Control of Independent-Wheel-Drive Electric Vehicle ( IWD-EV ) Via Composite Nonlinear Feedback Controller," 2014 First Int. Conf. Syst. Informatics, Model. Simul., pp. 88-93.

[22] M. H. Lee, S. Ki Ha, J. Y. Choi, and K. S. Yoon, "Improvement of the steering feel of an electric power steering system by torque map modification," J. Mech. Sci. Technol., vol. 19, no. 3, pp. 792-801, Mar. 2005.

[23] S. M. H. Fahami, H. Zamzuri, and S. A. Mazlan, "Development of estimation force feedback torque control algorithm for driver steering feel in vehicle steer by wire System: Hardware in the loop," Int. J. Veh. Technol., vol. $2015,2015$. 